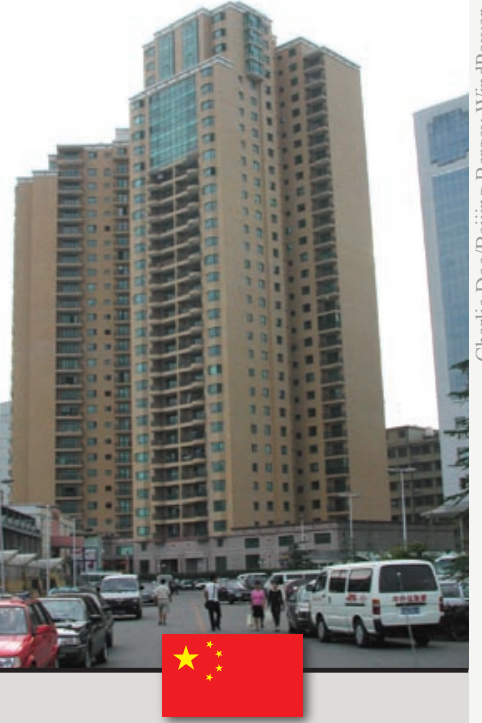

The Beijing Concordia International Apartment Building, where a geothermal heat pump system provides heating and cooling.

\title{
Renewable Energy in China
}

\section{Development of the Geothermal Heat Pump Market in China}

Geothermal Heat Pump (GHP) technology was introduced in China in the 1990s. Since that time, the Chinese market for GHP has developed significantly. With continuous commercialization of the technology combined with Chinese and U.S. government support, GHP could significantly contribute to China's effort to move toward more sustainable development.

In November 1997, the U.S. Department of Energy (DOE) and the Chinese Ministry of Science and Technology (MOST) signed a joint cooperation focused on development of the geothermal heat pump market in China. This agreement, also called Annex IV under the U.S.-China Protocol for Cooperation in the Fields of Energy Efficiency and Renewable Energy Technology Development and Utilization (U.S.-China Protocol), demonstrated the technical and economic feasibility of groundair GHP technology to enhance commercialization potential for the benefit of both China and the U.S.

This agreement has led to notable achievements. To date, 12 GHP demonstration projects have been developed in a joint effort by DOE, the U.S. GHP Consortium, and Beijing Jike Energy New Technology Development Company (Beijing Jike). Based on the first three completed projects, in April 2002 Beijing Jike and a U.S. company, Jacwill Services, were awarded a $\$ 309,000$ U.S. Trade and Development Agency (TDA) grant to expand the GHP market in China and leverage \$5-10 million in four additional projects in northern China. The projects demonstrated the benefits of ground-air GHP technology over conventional heating and cooling technologies, especially in the residential setting.

\section{Technical monitoring of energy and cost savings}

Ground-air GHP is the only dual heating and cooling technology that does not discharge wastewater or directly contribute to air pollution. Beijing Jike monitored the operation of the first three demonstration

Continues >

Table 1. Initial investment and operational costs of GHP system compared to a central air and heating system that runs on natural gas.

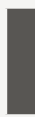

Unit price *
CNY $/ \mathrm{m}^{2}$
USD $/ \mathrm{m}^{2}$

Equipment cost

CNY 224.0

USD 27.0

Engineering cost

\section{Total investment}

CNY 136.0

USD 16.4

CNY 360.0

USD 43.5

Operational cost heating

CNY12.9

USD 1.6

Operational cost CNY 8.5

cooling USD 1.0

Cost of building space CNY 2500.0 required for equipment
USD 302.0

* Conversion rate used: $1 \mathrm{USD}=8.28 \mathrm{CNY}$.
? 
Table 2. Forecasted sales of GHP systems and units in public buildings over a five-year period in 14 provinces of China. Sales are in millions (m) or billions (bn).*

\begin{tabular}{|c|c|c|c|c|c|c|}
\hline & 2005 & 2006 & 2007 & 2008 & 2009 & 2010 \\
\hline \multirow[t]{2}{*}{ GHP systems } & CNY3.93 bn & CNY5.19 bn & CNY7.48 bn & CNY9.08 bn & CNY10.50 bn & CNY10.92 bn \\
\hline & USD474.83 m & USD627.06 m & USD $903.74 \mathrm{~m}$ & USD1.10 bn & USD1.27 bn & USD1.32 bn \\
\hline \multirow[t]{2}{*}{ GHP units } & CNY1.57 bn & CNY2.08 bn & CNY2.99 bn & CNY3.63 bn & CNY4.20 bn & CNY4.37 bn \\
\hline & USD189.69 m & USD251.31m & USD361.26 m & USD438.58 m & USD507.46 m & USD528.00 m \\
\hline
\end{tabular}

projects, one of which was the Beijing Concordia International Apartment Building pictured here, over the course of four years. This study demonstrated that the GHP systems are highly energy-efficient, and offer cost savings of $30-60 \%$ over boiler heating. In cities where natural gas is used, GHP technology costs $60 \%$ less than boiler heating; where coal is used, GHP use represents a $30 \%$ savings. In addition, the operating cost of GHP technology in summer is 40-60\% lower than that of traditional air conditioning. Table 1 illustrates the cost savings found in a 2002 analysis of the GHP system in Beijing's International Mansions at the Jiaheli Garden - the largest of the systems installed of the three demonstration projects. The cost of electricity in Beijing in 2002 was CNY0.39 per kilowatt-hour or USD0.047 per kilowatt-hour.

Each of the three U.S.-China demonstration projects completed to date has been successful, operating efficiently and without interruption. The average temperature of the rooms serviced by the projects is $26^{\circ} \mathrm{C}\left(79^{\circ} \mathrm{F}\right)$ in summer and $20^{\circ} \mathrm{C}\left(68^{\circ} \mathrm{F}\right)$ in winter (compared to China's national standard for cooling, $27^{\circ} \mathrm{C}$, and its standard for heating, $16^{\circ} \mathrm{C}$ ). The initial investment cost (including installation) is higher than that of air conditioning or boiler heating, but over just three years the savings garnered through lower operating costs pay for the initial investment.

Further, the three demonstration projects in Beijing have shown that compared with burning coal, use of GHP technology reduces the annual release of sulfur dioxide (SO2) by 11.2 tons; the annual release of carbon monoxide $(\mathrm{CO})$ and carbon dioxide $(\mathrm{CO} 2)$ combined is reduced by 473 tons; the release of air particulates is reduced by 41 tons; and yearly waste residue is reduced by 176 tons.* GHP technology is also much quieter than air conditioning; the air stream is stable and almost imperceptible, and the spread of germs and viruses is not a problem as it can be in central heating or cooling. Following on the success of the initial three projects, by the end of 2003 Jike had established 22 additional projects in the north, central and southern parts of China.

\footnotetext{
*Source: www.jikeghp.com
}

These additional projects also accomplished a significant savings over traditional technologies, and even improved upon the average winter temperature of the previous projects - above $22^{\circ} \mathrm{C}\left(71.6^{\circ} \mathrm{F}\right)$ and even as high as $26.2^{\circ} \mathrm{C}\left(79.2^{\circ} \mathrm{F}\right)$ when the outside air temperature fell below $-12^{\circ} \mathrm{C}\left(10.4^{\circ} \mathrm{F}\right)$. These 25 ground-air GHP system projects established by Beijing Jike. cover an area of $331,904 \mathrm{~m} 2$.

In fact, most of the ground-air GHP units in use in China have been imported from the U.S. The promotion and utilization of ground-air GHP technology in China has therefore moved into the large-scale phase.

\section{Market survey and analysis of potential GHP commercial growth.}

A recent market survey of 14 cities and provinces in China, supported by the U.S.-China Protocol, revealed that the predicted growth in sales for GHP units and building systems is significant. Growth was predicted in two ways. The first formula of calculation, reflected in Tables 2 and 3, combined the following values: the predicted annual growth of newly constructed buildings' floor space; the percentage of this floor space that is suitable for GHP utilization; the price of GHP system construction per square meter of floor space (for example, in public buildings the price of construction equals 320 Yuan [US\$39.00] per m2); and the rate of installation of GHP technology, based on preferential policies and the increase in commercialization. Table 2 shows the values obtained from this calculation for public not-for-profit buildings (such as schools and hospitals); Table 3 shows the results for commercial forprofit buildings.

China has been experiencing an electricity shortage since 2003, and much of this shortage is caused by air conditioning use during summer months - air conditioning accounts for more than $40 \%$ of total public energy consumption in China's developed cities during these months. GHP technology requires less electricity for cooling than a traditional air conditioner and presents a real solution to the need for energy conservation. Imports of GHP units (especially U.S. imports) and energy-efficient appliances have increased steadily 
Renewable Energy in China

Table 3. Forecasted sales of GHP systems and units in commercial buildings over a five-year period in 14 provinces of China. Sales are in millions (m) or billions (bn). *GHP units include GHP equipment; GHP systems include closed-loop heat exchangers, pump, pipelines, etc.

\begin{tabular}{|c|c|c|c|c|c|c|}
\hline & 2005 & 2006 & 2007 & 2008 & 2009 & 2010 \\
\hline \multirow{2}{*}{ GHP systems } & CNY449.0 m & CNY566.0 m & CNY808.0 m & CNY1.00 bn & CNY1.18 bn & CNY1.35 bn \\
\hline & USD54.25 m & USD68.38 m & USD97.63 m & USD121.31 m & USD142.93 m & USD163.47 m \\
\hline \multirow[t]{2}{*}{ GHP units } & CNY180.0 m & CNY226.0 m & CNY323.0 m & CNY402.0 m & CNY473.0 m & CNY541.0 m \\
\hline & USD21.75 m & USD27.31 m & USD39.03 m & USD $48.57 \mathrm{~m}$ & USD57.15 m & USD65.36 m \\
\hline
\end{tabular}

since 1999, while imports of household-size air conditioning units have declined. However, the price of Chinese air conditioners has decreased consistently over recent years, so the challenge for the promotion of GHP technology is to decrease its price similarly and demonstrate that the qualityprice ratio is considerably higher.

The market survey conducted by Beijing Jike also estimated the potential sales of GHP technology by predicting the growth of the air-conditioning market in all of China, for both commercial and non-commercial use. The survey found that between 2005 and 2010, sales of both GHP systems and units should increase at a yearly rate of about $17 \%$. Overall, the estimated sales of GHP systems in 2010 equals 7.65 billion Yuan-a 116\% total increase from the estimated sales for 2005. The future of market development for GHP technology appears promising, since the promotion of GHP and other environmentally responsible technologies is driven primarily by government policy, which increasingly favors sustainable development and environmental protection. In fact, this forecasted growth represents a conservative viewpoint. The predicted increase in demand is based largely on a growing desire for cooling and air conditioning, and much of this will be comprised of U.S. groundair technology.

\section{Looking toward the future.}

Between 1997 and 2004, China has seen great success in implementing GHP projects that have proven commercially, economically, and environmentally viable. For China, the GHP projects provide a welcome option for promoting environmental protection and energy efficiency in heating and cooling, while enjoying a low operating cost. For the U.S., the projects have proven beneficial in providing the U.S. GHP industry a significant advantage in the Chinese market and boosting U.S. business. Goals for the future include lowering the manufacturing cost of GHP units and increasing the market share for
GHP technology, and utilizing GHP technology in the rebuilding of China's "old city" areas.

Since the energy for GHP comes from the soil and is free, the expense for GHP-generated heating and cooling is lower than conventional sourceselectricity is required only for the heat pumps and controls. As the Chinese government looks toward achieving sustainable development goals, especially in light of the 2008 Green Olympics, energy consumption policy will be an important factor in promoting the use of GHP technology. Preferential pricing, tax benefits, and subsidies are all encouraged for the promotion of GHP. Thus, the development of GHP utilization depends on forward-looking government policies, and efforts to educate the public about the economical and environmental advantages of GHP technology.

The following fact sheets on renewable energy in China are available on the National Renewable Energy Laboratory's China Web site (www.nrel.gov/china).
- WB/GEF Renewable Energy Development Project
- Development of the Geothermal Heat Pump Market in China
- Grid Connected Wind Power in China
- Renewable Energy Policy in China:Overview
- Renewable Energy Policy in China: Financial Incentives
- Township Electrification Program
- China's Plan for Renewable Energy
- Brightness Rural Electrification Program
- Renewable Energy Business Partnerships in China
- Xiao Qing Dao Village Power Wind/Diesel Hybrid Pilot Project

These fact sheets were prepared by DOE/NREL and the China Renewable Energy Industries Association under the US/China Protocol for Cooperation in the Fields of Energy Efficiency and Renewable Energy Technology Development and Utilization.
An interior look at the system that services 501 units in the Beijing Concordia International Apartment Building.

For more information, please contact:

The National Renewable Energy Laboratory China Web site: www.nrel.gov/international/china

\author{
Li Xiuguo \\ Chinese Academy of Sciences \\ Room 301, Unit 2, Building 5 \\ Milan Sky, Yizhuang \\ Economic-Technological \\ Development Area \\ Beijing, China 100176 \\ Ph/Fax: +86-10-6789-8987 \\ E-mail: lixiuguo@263.net
}

\section{National Renewable Energy Laboratory 1617 Cole Boulevard Golden, Colorado 80401-3393 303-275-3000 • www.nrel.gov}

Operated for the U.S. Department of Energy Office of Energy Efficiency and Renewable Energy by Midwest Research Institute • Battelle

NREL/FS-710-39443

March 2006 